\title{
Papers
}

\section{Risk of complications of pregnancy in women with type 1 diabetes: nationwide prospective study in the Netherlands}

\author{
Inge M Evers, Harold W de Valk, Gerard H A Visser
}

\begin{abstract}
Objective To investigate maternal, perinatal, and neonatal outcomes of pregnancies in women with type 1 diabetes in the Netherlands.

Design Nationwide prospective cohort study.

Setting All 118 hospitals in the Netherlands.

Participants 323 women with type 1 diabetes who became pregnant between 1 April 1999 and 1 April 2000.

Main outcome measures Maternal, perinatal, and neonatal outcomes of pregnancy.

Results $84 \%(\mathrm{n}=271)$ of the pregnancies were planned. Glycaemic control early in pregnancy was good in most women $\left(\mathrm{HbA}_{1 \mathrm{c}} \leq 7.0 \%\right.$ in $75 \%(\mathrm{n}=212)$ of the population), and folic acid supplementation was adequate in $70 \%(\mathrm{n}=226) .314$ pregnancies that went beyond 24 weeks' gestation resulted in 324 infants. The rates of pre-eclampsia $(40 ; 12.7 \%)$, preterm delivery $(101 ; 32.2 \%)$, caesarean section $(139 ; 44.3 \%)$, maternal mortality $(2 ; 0.6 \%)$, congenital malformations $(29 ; 8.8 \%)$, perinatal mortality $(9 ; 2.8 \%)$, and macrosomia $(146 ; 45.1 \%)$ were considerably higher than in the general population. Neonatal morbidity (one or more complications) was extremely high $(260 ; 80.2 \%)$. The incidence of major congenital malformations was significantly lower in planned pregnancies than in unplanned pregnancies $(4.2 \%(n=11) v 12.2 \%(n=6)$; relative risk $0.34,95 \%$ confidence interval 0.13 to 0.88 ).

Conclusion Despite a high frequency of planned pregnancies, resulting in overall good glycaemic control (early) in pregnancy and a high rate of adequate use of folic acid, maternal and perinatal complications were still increased in women with type 1 diabetes. Neonatal morbidity, especially hypoglycaemia, was also extremely high. Near optimal maternal glycaemic control $\left(\mathrm{HbA}_{1 c} \leq 7.0 \%\right)$ apparently is not good enough.
\end{abstract}

\section{Introduction}

Pregnancy in women with type 1 diabetes mellitus is associated with an increased risk of congenital malformations, obstetric complications, and neonatal morbidity. These adverse outcomes are at least in part related to periconceptional care, especially the level of glycaemic control. Adequate preconceptional care reduces the frequency of congenital malformations and improves outcome of pregnancy. ${ }^{2}$ Motivating diabetic women to plan their pregnancies, to optimise glycaemic control, and to start folic acid supplementation before conception is thus an established goal. With this strategy, it is hoped that the goals of the St Vincent declaration can be achieved, with outcomes of pregnancy approximating those of non-diabetic women. ${ }^{3}$
Some authors have indeed found that outcomes of pregnancy in women with type 1 diabetes approached those of the non-diabetic population. ${ }^{145}$ However, most of these data were from centres with a special interest in diabetes and pregnancy and were therefore not representative of the total population. Three studies from large regions in the United Kingdom have shown that high levels of non-attendance at preconceptional care facilities and poor glycaemic control still exist among women with diabetes. ${ }^{6-8}$ Pregnancy outcome was poor in these studies, with high rates of congenital malformations. Data from nationwide populations are scarce, and most of them have been collected retrospectively. ${ }^{9-13}$ The outcomes are generally more favourable than in the United Kingdom regions but still do not meet the goals of the St Vincent declaration. To determine if these goals are being met in the Netherlands, we conducted a nationwide prospective study in pregnant women with type 1 diabetes during 1999-2000.

\section{Methods}

We asked all gynaecologists, internists, and diabetes nurse educators in the Netherlands to include all women with type 1 diabetes presenting for antenatal care between 1 April 1999 and 1 April 2000. All 118 Dutch hospitals participated, and a total of 364 eligible women were reported to the study coordinator (IME). We excluded $41(11 \%)$ women because of first trimester spontaneous abortion $(23 ; 6 \%)$, diagnosis of type 2 or secondary diabetes $(16 ; 4 \%)$, or loss to follow up $(2 ; 1 \%)$. We report here analyses concerning the remaining 323 pregnancies. All participants gave written informed consent.

Eligible women filled in questionnaires at inclusion (at around 10 weeks' gestation), at the end of the first trimester (around 17 weeks), and during the third trimester (around 34 weeks). Internists filled in a questionnaire including general characteristics, medical history, and diabetes related items; gynaecologists gave information about the outcome of pregnancy; and paediatricians filled in a questionnaire to collect information of the newborns.

We recorded maternal characteristics (age, body mass index, marital status, ethnic origin, education level, alcohol use, smoking habits, and parity), duration of diabetes, presence of chronic complications (retinopathy, nephropathy, macroangiopathy), and treatment of diabetes (continuous subcutaneous insulin infusion or multiple insulin treatment, human insulin or analogue (lispro) insulin).

\section{Glycaemic control during pregnancy}

We collected $\mathrm{HbA}_{1 \mathrm{c}}$ concentrations during the first $(\mathrm{n}=283)$, second $(n=276)$, and third trimesters $(n=262)$ from the local hos- 
pitals. We adopted a standardisation procedure to adjust for variations between the local $\mathrm{HbA}_{\mathrm{lc}}$ assays. ${ }^{14}$ We divided glycaemic control into three categories: mean $\mathrm{HbA}_{1 c} \leq 6.0 \%$ (within normal range; "excellent"), mean $\mathrm{HbA}_{1 c} \quad 6.1-7.0 \%$ (2-4 standard deviations from mean; "good"), and mean $\mathrm{HbA}_{1 \mathrm{c}}>7.0 \%$ ("not optimal"). We also asked the women to send a self obtained capillary blood sample to a central laboratory (Queen Beatrix Hospital, Winterswijk, Netherlands) for determination of $\mathrm{HbA}_{1 c}$ (HPLC, normal reference value 4.0-6.0\%) early in pregnancy at about 10 weeks. We included only samples received between 8 and 14 weeks' gestation $(n=227)$.

Severe hypoglycaemia occurring during the first and third trimesters was recorded. We defined severe hypoglycaemia as all episodes for which external help was needed, including hypoglycaemic coma. ${ }^{15} 16$

\section{Outcome measures}

Obstetric complications-We defined pre-eclampsia as a diastolic blood pressure $\geq 90 \mathrm{~mm} \mathrm{Hg}$ on two occasions at least four hours apart in the second half of pregnancy in a previously normotensive woman and proteinuria $(\geq 300 \mathrm{mg} / 24$ hours $) .{ }^{17} \mathrm{In}$ patients with pre-existing hypertension, pre-eclampsia was diagnosed when proteinuria occurred de novo in the second half of pregnancy.

Perinatal outcome - We divided congenital malformations into major and minor malformations. We classified a malformation as major if it was fatal, potentially life threatening, likely to lead to serious handicap or major cosmetic defect, or requiring major surgery. We classified chromosomal abnormalities as major malformations. We included fetuses of $\geq 24$ weeks' gestation, weighing $\geq 500 \mathrm{~g}$, or both $(\mathrm{n}=324)$ and therapeutic abortions due to congenital malformations or chromosomal abnormalities $(\mathrm{n}=4)$. We defined perinatal mortality as fetal losses from 24 weeks of gestation, $\geq 500 \mathrm{~g}$, or both, together with all postnatal deaths up to seven days after birth. We grouped birth weight by centiles according to the official Dutch growth charts, published in $1970,{ }^{18}$ and according to a growth chart based on the 1998 Dutch perinatal database (including 181000 deliveries). ${ }^{19}$ We defined macrosomia as birth weight above the 90th centile corrected for gestational age, sex, and parity. We defined severe macrosomia as birth weight above the 97.7 th centile.

Neonatal outcome-We defined neonatal hypoglycaemia as blood glucose $<2.6 \mathrm{mmol} / \mathrm{l}$ and severe neonatal hypoglycaemia as blood glucose $<2.0 \mathrm{mmol} / \mathrm{l} .{ }^{20}$ We defined infant respiratory distress syndrome according to Giedion et al and according to clinical symptoms of respiratory stress. ${ }^{21}$

We compared maternal and perinatal outcomes with national data from the 1998 Dutch perinatal database and with data from Statistics Netherlands. ${ }^{192-27}$ Information about pregnancy, delivery, and puerperium of pregnancies with a duration of at least 16 completed weeks is collected in the Dutch perinatal database, which contains data on $91 \%$ of all deliveries.

\section{Statistical analysis}

We used SPSS for the statistical analyses. ${ }^{28}$ We present data as means with standard deviations or as percentages. We compared continuous data by using Student's $t$ test (and non-parametric tests if appropriate) and categorical data by using the $\chi^{2}$ test or Fisher's exact test. We considered associations with $\mathrm{P}<0.05$ to be significant. We also calculated relative risks and associated $95 \%$ confidence intervals.
Table 1 General characteristics of study population. Values are numbers (percentages) unless stated otherwise

Women with type 1 diabetes $(n=323)$

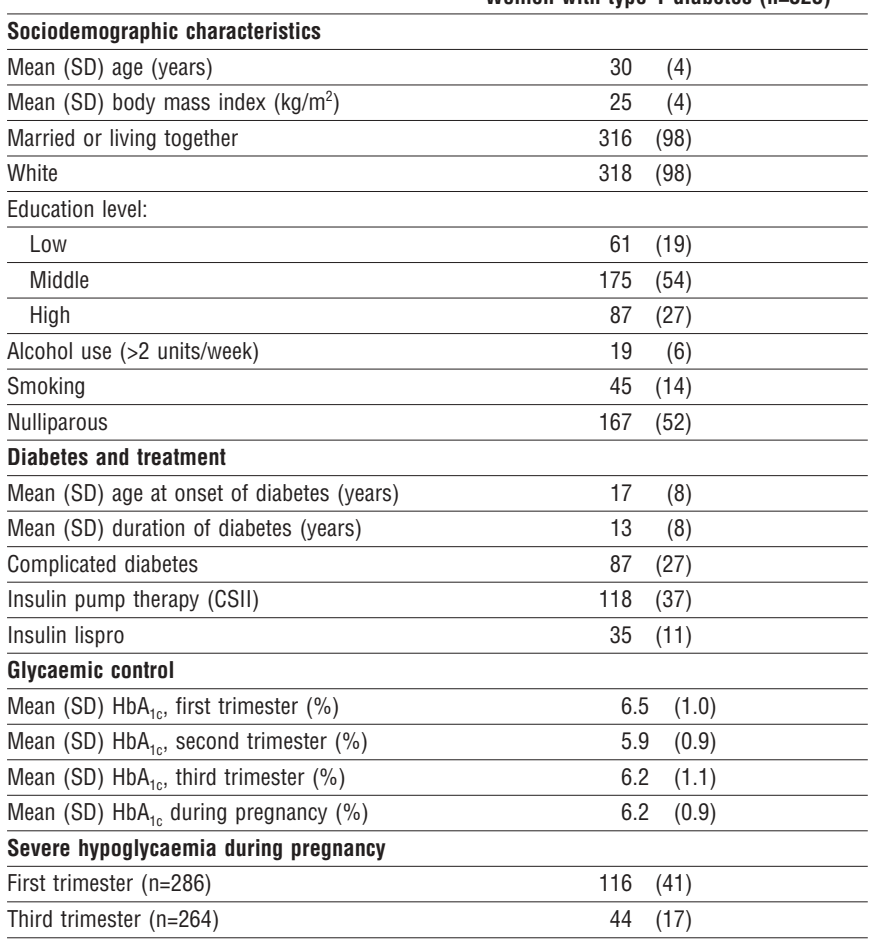

CSII=continuous subcutaneous insulin infusion.

\section{Results}

The 323 pregnancies in women with type 1 diabetes included four therapeutic abortions, two due to major congenital malformations (spina bifida and anencephaly) and two due to chromosomal abnormalities. One maternal death occurred at 17 weeks' gestation, and four other pregnancies ended before 24 weeks of gestation, leaving 314 ongoing pregnancies. Of these, eight were twin pregnancies and one was a triplet pregnancy, resulting in 324 infants born after 24 weeks of gestation.

\section{Maternal characteristics}

Table 1 shows the characteristics of the 323 women. Maternal age, parity, and race did not differ significantly from those of the general pregnant population. Mean first trimester $\mathrm{HbA}_{1 \mathrm{c}}$ was $6.5 \%$ (SD 0.7\%); glycaemic control was excellent $\left(\mathrm{HbA}_{\mathrm{lc}} \leq 6.0 \%\right)$ in $90(32 \%)$, good $(6.1-7.0 \%)$ in $122(43 \%)$, and not optimal $(>7.0 \%)$ in $71(25 \%)$ of the pregnancies. Mean $\mathrm{HbA}_{\mathrm{lc}}$ during pregnancy was $6.2 \%(0.9 \%)$; excellent in $113(40 \%)$, good in 121 $(43 \%)$, and not optimal in $49(17 \%)$ pregnancies. Mean $\mathrm{HbA}_{1 \mathrm{c}}$ early in pregnancy determined in the central laboratory was $6.7 \%(0.7 \%)$. Two hundred and seventy one $(84 \%)$ of the women had planned their pregnancy, and $226(70 \%)$ had started folic acid supplementation before conception.

\section{Maternal outcome}

Pre-eclampsia-More than 12\% of the pregnancies were complicated by pre-eclampsia (table 2), which is 12 times higher than in the reference group.

Prematurity and caesarean section-The rate of prematurity (that is, delivery before 37 weeks of gestation) was $32.2 \%$ (11.8\% (37) spontaneous and 20.4\% (64) induced), a more than fourfold increase in risk compared with the national population. Reasons for induced preterm delivery were pre-eclampsia (26, 40.6\%), fetal distress (20,31.3\%), macrosomia (5, 7.8\%), and others (13, 20.3\%). 
Table 2 Maternal outcome of pregnancies complicated by diabetes mellitus type 1 compared with national data

\begin{tabular}{|c|c|c|c|c|}
\hline \multirow[b]{2}{*}{ Outcome } & \multicolumn{2}{|c|}{ Type 1 diabetes ( $n=314$ ) } & \multirow[b]{2}{*}{ National data $(\mathrm{n}=196 \mathrm{981})(\%)$} & \multirow[b]{2}{*}{ Relative risk $(95 \% \mathrm{CI})$} \\
\hline & No & $\%(95 \% \mathrm{Cl})^{*}$ & & \\
\hline Pre-eclampsia & 40 & 12.7 (9.0 to 16.4) & 1.05 & $12.1 \quad(9.0$ to 16.1$)$ \\
\hline Prematurity & 101 & $32.2(27.0$ to 37.4$)$ & 7.1 & 4.5 (3.8 to 5.3$)$ \\
\hline Maternal mortality & 2 & 0.6 & 0.01 & 60.0 (14.3 to 249.6$)$ \\
\hline
\end{tabular}

The rate of caesarean section was $44.3 \%(23.9 \%(\mathrm{n}=75)$ primary and $20.4 \%$ (64) secondary), an almost fourfold increase in risk. Reasons for a primary caesarean section were fetal distress (23, $30.7 \%)$, pre-eclampsia $(19,25.3 \%)$, macrosomia $(15,20.0 \%)$, breech presentation $(9,12.0 \%)$, and others $(9,12.0 \%)$. Reasons for a secondary caesarean section were failed induction or obstructed labour $(33,51.6 \%)$, fetal distress $(25,39.1 \%)$, and others $(6,9.3 \%)$.

Maternal mortality-Two $(0.6 \%)$ maternal deaths occurred. One woman probably died owing to severe hypoglycaemia followed by a cardiac arrest at 17 weeks' gestation. The other woman died during parturition owing to an amniotic fluid embolism.

\section{Perinatal and neonatal outcome}

Congenital malformations-Congenital malformations occurred in $29(8.8 \%)$ of the infants (table 3), a threefold increased risk compared with the national population. Major congenital malformations $(n=18)$ comprised cardiovascular anomalies (8), urogenital anomalies (4), and neural tube defects (3, including one case of caudal regression syndrome). Minor congenital malformations (11) were anomalies such as hypospadia, vertebral anomalies, and clubfoot. Incidence of congenital malformations was greater with a higher first trimester $\mathrm{HbA}_{1 \mathrm{c}}-6.3 \%$ (6) for $\mathrm{HbA}_{\mathrm{lc}} 4.0-6.0 \%, 6.4 \%$ (8) for $\mathrm{HbA}_{\mathrm{lc}}$ 6.1-7.0\%, and $12.9 \%$ (9) for $\mathrm{HbA}_{1 \mathrm{c}}>7.0 \%$. (First trimester $\mathrm{HbA}_{1 \mathrm{c}}$ was determined in 23 out of 29 pregnancies with a malformed infant.) We found the same association when we used centrally determined $\mathrm{HbA}_{1 \mathrm{c}}$ levels (data not shown). The incidence of (all) congenital malformations was $6.3 \%(\mathrm{n}=14)$ in the pregnancies with excellent or good first trimester $\mathrm{HbA}_{\mathrm{lc}}(\leq 7.0 \%)$ compared with $12.9 \%$ (9) in those with non-optimal first trimester $\mathrm{HbA}_{1 \mathrm{c}}$ (>7.0\%) (relative risk $0.49,95 \%$ confidence interval 0.22 to 1.1 ). The incidences of major congenital malformations in these two groups were $2.7 \%$ (6) and $10.0 \%$ (7) (relative risk $0.27,0.09$ to $0.79)$.

Perinatal mortality-Nine perinatal deaths (2.8\%; 27.8/1000 births) occurred-six stillbirths and three neonatal deaths. Table 4 summarises the causes of death.

Macrosomia-Mean birth weight of the 324 infants was 3454 (SD 829) g at 37.0 (2.7) weeks of gestation; 170 (52.5\%) infants were macrosomic, including 92 (28.4\%) severely macrosomic, according to the official growth charts. The equivalent percentages were $45.1 \%$ (table 3 ) and $24.1 \%(\mathrm{n}=78)$ according to the growth charts based on data collected in 1998 (fig). Seventy seven (23.8\%) infants had a birth weight $>4000$ g, including 23 $(7.1 \%)$ weighing $>4500 \mathrm{~g}$. First, second, and third trimester $\mathrm{HbA}_{1 c}$ and mean $\mathrm{HbA}_{1 c}$ during pregnancy were slightly but significantly higher in the women with a macrosomic infant (mean $\mathrm{HbA}_{1 c}$ during pregnancy $6.4 \%(\mathrm{SD} 0.9 \%) v 6.0 \%(0.9 \%) ; \mathrm{P}=0.001)$.

Neonatal outcome-Table 5 summarises neonatal outcomes. Neonatal morbidity (one or more complications) was present in $260(80.2 \%)$ of infants. Shoulder dystocia and neonatal hypoglycaemia occurred significantly more often in macrosomic than in non-macrosomic infants-27.4\% $(\mathrm{n}=20) v 4.7 \%(5)$ (relative risk $5.8,2.3$ to 14.7 ) and $75.4 \%$ (107) v 54.5\% (91) (relative risk $1.4,1.2$ to 1.6). Hyperbilirubinaemia, respiratory disorders, hypertrophic cardiomyopathy, and asphyxia were significantly more common in preterm infants (all $\mathrm{P}<0.005)$.

Table 3 Perinatal outcome of pregnancies complicated by diabetes mellitus type 1 compared with national data

\begin{tabular}{|c|c|c|c|c|}
\hline \multirow[b]{2}{*}{ Outcome } & \multicolumn{2}{|c|}{ Type 1 diabetes ( $n=324)$} & \multirow[b]{2}{*}{ National data $(\mathrm{n}=200679)(\%)$} & \multirow[b]{2}{*}{ Relative risk $(95 \% \mathrm{Cl})$} \\
\hline & No & $\%(95 \% \mathrm{CI})$ & & \\
\hline Congenital malformations: & 29 & $8.8 \quad$ (5.7 to 11.9) & 2.6 & 3.4 (2.4 to 4.8$)$ \\
\hline Major & 18 & 5.5 & - & - \\
\hline Perinatal mortality & 9 & 2.8 (1.05 to 4.6$)$ & 0.8 & 3.5 (1.8 to 6.7$)$ \\
\hline Macrosomia (>90th centile) & 146 & 45.1 (39.7 to 50.5) & $10.0^{*}$ & $4.5(4.0$ to 5.1$)$ \\
\hline
\end{tabular}

${ }^{*} n=181000$.

Table 4 Characteristics of nine perinatal deaths in pregnancies of women with type 1 diabetes

\begin{tabular}{|c|c|c|c|c|c|c|c|}
\hline Case & $\begin{array}{l}\text { First trimester } \mathrm{HbA}_{1 \mathrm{c}} \\
(\%)\end{array}$ & $\begin{array}{l}\text { Mean } \mathrm{HbA}_{1 \mathrm{c}} \text { during } \\
\text { pregnancy }(\%)\end{array}$ & Congenital malformations & Obstetric complications & $\begin{array}{l}\text { Gestational age at } \\
\text { delivery (weeks) }\end{array}$ & $\begin{array}{l}\text { Size at } \\
\text { birth }\end{array}$ & Cause of death \\
\hline $1^{\star} \dagger$ & 5.9 & 5.8 & - & Pre-eclampsia & 24 & AGA & Termination of pregnancy \\
\hline $2^{\star} \dagger$ & 5.9 & 5.8 & - & Pre-eclampsia & 24 & AGA & Termination of pregnancy \\
\hline $4^{*}$ & 8.3 & 8.0 & VSD, renal agenesis & - & 26 & AGA & Congenital malformations \\
\hline 5 & - & - & Hypospadia & IUGR & 27 & SGA & Multiple organ failure \\
\hline 6 & 5.6 & 5.7 & Coarctatio aortae & $\begin{array}{l}\text { Placental abruption (partial), } \\
\text { asphyxia }\end{array}$ & 28 & AGA & Prematurity \\
\hline $7^{\star}$ & 6.9 & 6.0 & - & IUGR & 29 & SGA & IUGR \\
\hline $8^{\star}$ & 6.6 & 5.8 & - & - & 36 & AGA & Unexplained \\
\hline 9 & 5.5 & 5.5 & - & Asphyxia & 38 & AGA & Asphyxia \\
\hline
\end{tabular}

$\mathrm{AGA}=$ appropriate for gestational age; $\mathrm{SGA}=$ small for gestational age; IUGR=intrauterine growth retardation; VSD=ventricle septum defect.

${ }^{*}$ Stillbirth.

†Twin pregnancy. 


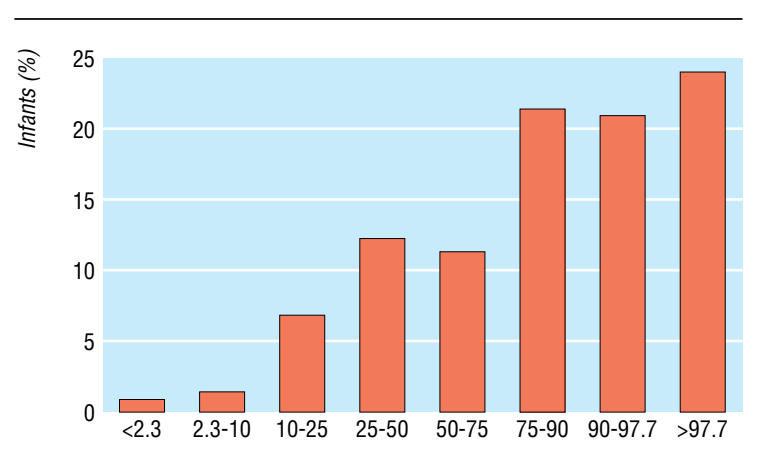

Birth weight $(g)$

Distribution of birth weight among 324 infants of women with type 1 diabetes (reference data from Dutch perinatal database, $1998^{19}$ )

Maternal, perinatal, and neonatal outcomes (except for congenital malformations) in women with good glycaemic control $\left(75 \%\right.$, first trimester $\left.\mathrm{HbA}_{1 \mathrm{c}} \leq 7.0 \%\right)$ were comparable to those in women with less good control.

\section{Planned pregnancies}

First trimester $\mathrm{HbA}_{1 \mathrm{c}}$ was significantly lower in the planned pregnancies than in the unplanned ones $(6.4 \%$ (SD 0.9\%) v $7.0 \%$ $(1.4 \%) ; \mathrm{P}<0.001)$. The incidence of major congenital malformations was significantly lower in the planned pregnancies $(4.2 \%$ $(\mathrm{n}=11)$ v $12.2 \%$ (6); relative risk $0.34,0.13$ to 0.88$)$; other outcomes did not differ.

\section{Severe hypoglycaemia during pregnancy}

Forty four (41\%) of 264 women were affected by severe hypoglycaemia during the first trimester, and 116/286 (17\%) of the women were affected during the third trimester. Mean $\mathrm{HbA}_{1 c}$ levels were slightly but significantly lower in these women than in women who did not experience hypoglycaemia $(6.4 \%$ (SD $0.8 \%)$ $v 6.7 \%(0.7 \%) ; \mathrm{P}=0.03)$. The incidence of macrosomia was significantly lower in women affected by severe hypoglycaemia $(37.5 \%(\mathrm{n}=48)$ v $56.4 \%$ (92); relative risk $0.66,0.51$ to 0.85$)$. All other outcomes were similar.

\section{Use of lispro during pregnancy}

Thirty five (11\%) of the women used insulin lispro during pregnancy. The $\mathrm{HbA}_{1 \mathrm{c}}$ levels, occurrence of severe hypoglycaemia, and rate of congenital malformations in these women did not differ from those in women using human insulin.

Table 5 Neonatal outcome of 324 infants of women with type 1 diabetes

\begin{tabular}{lc} 
Outcome & No (\%) \\
\hline Shoulder dystocia*: & $25(14)$ \\
\hline Clavicle fracture & $4(2)$ \\
\hline Erb palsy & $1(1)$ \\
\hline Neonatal hypoglycaemia: & $207(64)$ \\
\hline$<2.6 \mathrm{mmol} / \mathrm{l}$ & $141(44)$ \\
\hline$<2.0 \mathrm{mmol} / \mathrm{l}$ & $82(25)$ \\
\hline Hyperbilirubinaemiat: & $47(15)$ \\
\hline Respiratory disorders: & $17(5)$ \\
\hline Infant respiratory distress syndrome & $22(7)$ \\
\hline Wet lung & $8(2)$ \\
\hline Others & $16(5)$ \\
\hline Hypertrophic cardiomyopathy & $16(5)$ \\
\hline Apgar score $<7$ at five minutes &
\end{tabular}

$* \%$ of vaginal deliveries $(n=179)$.

†Needing treatment (phototherapy)

‡Clinical diagnosis of hypertrophic cardiomyopathy.

\section{Discussion}

This nationwide study shows that the goals of the St Vincent declaration for outcome of pregnancy in women with diabetes are still not being met. Although most women planned their pregnancy and prepared well (that is, had good glycaemic control and adequate folic acid supplementation), outcome was still not comparable to that of the general population. The risks of congenital malformations, macrosomia, and pre-eclampsia were increased threefold to 12-fold, and neonatal morbidity, especially hypoglycaemia, was also extremely high. These results are in agreement with data from regions of the United Kingdom, but those studies reported a high level of non-attendance at preconceptional care facilities and poor glycaemic control.

\section{Glycaemic control}

The American Diabetes Association has stated that in pregnancy tight glycaemic control is accomplished when $\mathrm{HbA}_{1 \mathrm{c}}$ is within $1 \%$ above the upper limit of the normal range (4.0-6.0\%). $\mathrm{HbA}_{\mathrm{lc}}$ concentrations $\leq 7.0 \%$ are assumed to be associated with rates of congenital malformations and macrosomia no greater than those in pregnancies in non-diabetic women. ${ }^{29}$ However, our study shows that such levels of control are not good enough to prevent these complications. This indicates that current criteria for strict glycaemic control are not "safe" enough or that $\mathrm{HbA}_{1 \mathrm{c}}$ does not sufficiently reflect short term glucose variability (hypoglycaemia and hyperglycaemia). ${ }^{30}$ Recently, the second possibility has indeed been shown with the continuous glucose monitoring system..$^{32}$

Congenital malformations were related (but not significantly) to $\mathrm{HbA}_{10}$, but the incidence was higher than that of the general population, even with normal and almost normal $\mathrm{HbA}_{1 \mathrm{c}}$ values. This also points to an effect of glucose variability rather than of $\mathrm{HbA}_{1 c^{\circ}}$. The same can be concluded from the high incidence of macrosomia. ${ }^{33}$ This incidence was much higher than that published by other authors, despite overall adequate $\mathrm{HbA}_{1 \mathrm{c}}$ levels. ${ }^{11}{ }^{13} 34{ }_{35} \mathrm{HbA}_{1 c}$ was the most powerful predictor for macrosomia, but its predictive capacity was only weak (explained variance $<5 \%)^{33}$

Almost all women in our study were white (98\%) and married (98\%), and $81 \%$ were medium to highly educated. This probably explains the high rate of planned pregnancies (84\%) compared with other studies, in which percentages of $26 \%$ and $59 \%$ have been reported. ${ }^{36}{ }^{37}$ The organisation of the Dutch healthcare system, which allows access to health care for everyone, may also have played a role. The incidence of major congenital malformations was very high in the unplanned pregnancies. Further lowering the rate of unplanned pregnancies in the Netherlands is thus an important goal to achieve. This recommendation is also supported by the national service framework for diabetes in the United Kingdom. ${ }^{38}$

\section{Neonatal morbidity}

In general, neonatal morbidity (one or more complications) was extremely high $(>80 \%)$. Neonatal hypoglycaemia in particular occurred very frequently and more often than reported by other authors, although comparison is difficult owing to differences in definition. Abnormalities of the brain on magnetic resonance imaging have been described if neonatal glucose falls below 2.6 mmol/l. ${ }^{39}$ The high occurrence rate of such low values (and even of values below $2.0 \mathrm{mmol} / \mathrm{l}$ ) indicates that more aggressive preventive management is appropriate. Appropriate for gestational age infants had a lower risk of neonatal hypoglycaemia than other infants, but the incidence of hypoglycaemia was still unexpectedly high in this group. This deserves attention from paedia- 


\section{What is already known on this topic}

Pregnancy in women with type 1 diabetes mellitus is associated with increased risk of maternal, perinatal, and neonatal complications

Data from nationwide populations are scarce, and most have been collected retrospectively

\section{What this study adds}

Despite overall adequate glycaemic control $\left(\mathrm{HbA}_{\mathrm{lc}} \leq 7.0 \%\right)$, maternal and perinatal complications remained high in women with type 1 diabetes

The very high incidence of neonatal hypoglycaemia (64.1\%) occurred in both macrosomic and non-macrosomic infants; neonatologists should pay special attention to this

Population data are of great importance in assessing the real effects of current treatment strategies

tricians. All other neonatal morbidity data were comparable to other studies on type 1 diabetic pregnancies. ${ }^{11} 133440$ The high macrosomia rate in our study may (partly) explain the high incidence of neonatal morbidity.

\section{Conclusion}

Despite a high frequency of planned pregnancies, resulting in overall good glycaemic control (early) in pregnancy and a high rate of adequate use of folic acid, maternal and perinatal complications were still greatly increased in women with type 1 diabetes. Neonatal morbidity, especially hypoglycaemia, was also extremely high. The aims of the St Vincent declaration have not yet been achieved. Near optimal maternal glycaemic control $\left(\mathrm{HbA}_{1 \mathrm{c}} \leq 7.0 \%\right)$ is apparently not good enough.

We thank all the gynaecologists, paediatricians, internists, and diabetes nurse educators in the Netherlands for including their patients in this nationwide study; the women who participated for their willingness to fill in the questionnaires; PRISMANT Health Care Information who gave us permission to use their perinatal register of 1998; and TNO Prevention and Health for their statistical analysis of this register.

Contributors: All authors conceived and designed the study, drafted the manuscript, and approved the final manuscript. IME analysed and interpreted the data. HWdV and GHAV interpreted the data. GHAV will act as guarantor for the paper.

Funding: Novo Nordisk Farma BV, Alphen aan De Rijn, the Netherlands. Competing interests: None declared.

Ethical approval: The study was approved by the medical ethics committee of the University Medical Center Utrecht.

1 Steel JM, Johnstone FD, Hepburn DA, Smith AF. Can pre-pregnancy care of diabetic women reduce the risk of abnormal babies? BMJ 1990:301:1070-4

2 Willhoite MB, Bennert HW Jr, Palomaki GE, Zaremba MM, Herman WH, Williams JR, et al. The impact of preconception counseling on pregnancy outcomes: the experience of the Maine diabetes in pregnancy program. Diabetes Care 1993;16:450-5.

3 Diabetes care and research in Europe: the Saint Vincent declaration. Diabet Med 1990;7:360.

4 Fuhrmann K, Reiher H, Semmler K, Fischer F, Fischer M, Glockner E. Prevention of congenital malformations in infants of insulin-dependent mothers. Diabetes Care 1983;6:219-223.

5 Kitzmiller JL, Gavin LA, Gin GD, Jovanovic-Peterson L, Main EK, Zigrang WD. Preconception care of diabetes: glycemic control prevents congenital anomalies. JAMA 1991;265:731-6.

6 Casson IF, Clarke CA, Howard CV, McKendrick O, Pennycook S, Pharoah POD, et al Outcomes of pregnancy in insulin dependent diabetic women: results of a five year population cohort study. $B M J$ 1997;315:275-8.

7 Hawthorne G, Robson S, Ryall EA, Sen D, Roberts SH, Ward Platt MP. Prospective population based survey of outcome of pregnancy in diabetic women: results of the Northern Diabetic Pregnancy Audit, 1994. BMJ 1997;315:279-81.
8 Platt MJ, Stanisstreet M, Casson IF, Howard CV, Walkinshaw S, Pennycook S, et al. St. Vincent's declaration 10 years on: outcomes of diabetic pregnancies. Diabet Med 2002;19:216-20.

9 Jervell J, Bjerkedal T, Moe N. Outcome of pregnancies in diabetic mothers in Norway 1967-1976. Diabetologia 1980;18:131-4.

10 Hanson U, Persson B, Thunell S. Relationship between haemoglobin $A_{1 c}$ in early type 1 (insulin-dependent) diabetic pregnancy and the occurrence of spontaneous abortion and fetal malformation in Sweden. Diabetologia 1990;33:100-4.

11 Hanson U, Persson B. Outcome of pregnancies complicated by type 1 insulin-dependent diabetes in Sweden: acute pregnancy complications, neonatal mortality and morbidity. Am J Perinat 1993;4:330-3.

12 Cnattingius S, Berne C, Nordström ML. Pregnancy outcome and infant mortality in diabetic patients in Sweden. Diabet Med 1994;11:696-700.

13 Gestation and Diabetes in France Study Group. Multicenter survey of diabetic pregnancy in France. Diabetes Care 1991;14:994-1000.

14 Tamborlane WV, Champion MC, Rizza RA, Service FJ, Bergenstal RM for the KROC Collaborative Study Group. Observations on control of glycemia with conventional insulin therapy or continuous subcutaneous insulin infusion. Diabetes 1985;34(suppl 3):22-6.

15 Tattersall RB. Frequency, causes and treatment of hypoglycaemia. In: Frier BM, Fisher BM, eds. Hypoglycaemia in clinical diabetes. Chichester:John Wiley and Sons, 1999:55-87.

16 Diabetes Control and Complications Trial Research Group. The effect of intensive treatment of diabetes on the development and progression of long-term complications in insulin-dependent diabetes mellitus. N Engl J Med 1993;329:977-86.

17 Davey DA, Macgillivray I. The classification and definition of the hypertensive disorders of pregnancy. Am J Obstet Gynecol 1988;158:892-8.

18 Kloosterman GJ. On intra-uterine growth. Int J Obstet Gynecol 1970:8:895-912.

19 Anthony S, van der Pal-de Bruin KM, Graafmans WC, Dorrepaal CA, Borkent-Polet M, van Hemel OJS, et al. The reliability of perinatal and neonatal mortality rates: differential under-reporting in linked professional registers vs. Dutch civil registers. Paediatr Perinatal Epidemiol 2001;15:306-14.

20 Gregory JW, Aynsley-Green A. The definition of hypoglycaemia. Baillieres Clin Endocrinol Metab 1993;7:587-90.

21 Giedion A, Haefliger H, Dangel P. Acute pulmonary X-ray changes in hyaline membrane disease treated with artificial ventilation and positive end-expiratory pressure (PEP). Pediatr Radiol 1973;1:145-52.

22 Landelijke verloskunde registratie (LVR) 1998. Utrecht: SIG Zorginformatie, 1999.

23 Elferink-Stinkens PM, Van Hemel OJ, Brand R, Merkus JM. The perinatal database of the Netherlands. Eur J Obstet Gynecol Reprod Biol 2001;94:125-38.

24 Van Eyck J, de Boer WF, Arabin B. Epidemiology of preeclampsia in the Netherlands. Abstract book, 11th World Congress of the International Society for the Study of Hypertension in Pregnancy, Kobe, 1998 (S10-2).

25 Schuitemaker N, van Roosmalen J, Dekker G, van Dongen P, van Geijn H, Bennebroek Gravenhorst J. Confidential enquiry into maternal deaths in the Netherlands 1983-1992. Eur J Obstet Gynecol Reprod Biol 1998;79:57-62.

26 Bennebroek Gravenhorst J, van Roosmalen J, Schuitemaker N, Briet JW, Visser W, Pel M, et al. Toename van de moedersterfte een reden tot ongerustheid? Ned Tijdschr Obstet Gynaecol 2001;114:75-6.

27 Statistics Netherlands (CBS). http://statline.cbs.nl.

28 Altman DG. Practical statistics for medical research. London: Chapman and Hall, 1991.

29 American Diabetes Association. Preconception care of women with diabetes. Diabetes Care 2002;25(suppl 1):S82-4.

30 Kyne-Grzebalski D, Wood L, Marshall SM, Taylor R. Episodic hyperglycaemia in pregnant women with well-controlled type 1 diabetes mellitus: a major potential factor underlying macrosomia. Diabet Med 1999;16:702-6.

31 Cheyne E, Kerr D. Making sense of diabetes: using a continuous glucose sensor in clinical practice. Diabetes Metab Res Rev 2002;18:S43-8.

32 Kerssen A, Evers IM, de Valk HW, Visser GHA. Poor glucose control in women with type 1 diabetes mellitus and 'safe' hemoglobin $\mathrm{A}_{\mathrm{lc}}$ in the first trimester of pregnancy. $J$ Matern Fetal Neonatal Med 2003;13:309-13.

33 Evers IM, de Valk HW, Mol BWJ, Ter Braak EWMT, Visser GHA. Macrosomia despite good glycaemic control in type 1 diabetic pregnancy: results of a nationwide study in the Netherlands. Diabetologia 2002;45:1484-9.

34 Vääräsmaki MS, Hartikainen A, Anttila M, Pramila S, Koivisto M. Factors predicting peri- and neonatal outcome in diabetic pregnancy. Early Hum Dev 2000;59:61-70.

35 Taylor R, Lee C, Kyne-Grzebalski D, Marshall SSM, Davison JM. Clinical outcomes of pregnancy in women with type 1 diabetes. Obstet Gynecol 2002;99:537-41.

36 Holing EV, Beyer CS, Brown ZA, Connell FA. Why don't women with diabetes plan their pregnancies? Diabetes Care 1998;21:889-95.

37 St. James PJ, Younger MD, Hamilton BD, Waisbren SE. Unplanned pregnancies in young women with diabetes: an analysis of psychosocial factors. Diabetes Care 1993;16:1572-8.

38 Department of Health. National service framework for diabetes. London: Stationery Office, 2001.

39 Kinnala A, Rikalainen H, Lapinleimu H, Parkkola R, Kormano M, Kero P. Cerebral magnetic resonance imaging and ultrasonography findings after neonatal hypoglycemia Pediatrics 1999:103:794-9.

40 Reece EA, Homko CJ. Infant of the diabetic mother. Semin Perinatol 1994;18:459-69. (Accepted 18 February 2004)

doi 10.1136/bmj.38043.583160.EE

Department of Obstetrics, University Medical Center Utrecht, PO Box 85090, 3508 AB, Utrecht, Netherlands

Inge M Evers registrar

Gerard H A Visser professor of obstetrics

Department of Internal Medicine and Endocrinology, University Medical Center Utrecht

Harold W de Valk consultant

Correspondence to: I M Evers ingwil@worldonline.nl 